\title{
Polyurethanization temperature effect to the thermal behaviour of cellulose - fiber based hybrid polyurethane
}

\author{
Herald Kurnia Adi ${ }^{1}$, Fauzia Hanum Ikhwan ${ }^{2}$, Hasyim Aidilichsan Muliawan ${ }^{3}$, and \\ Mochamad Chalid* \\ ${ }^{1}$ Department of Metallurgy and Materials Engineering, Universitas Indonesia, UI Depok New \\ Campus, Depok 16424, West Java, Indonesia \\ ${ }^{2}$ Department of Metallurgy and Materials Engineering, Universitas Indonesia, UI Depok New \\ Campus, Depok 16424, West Java, Indonesia \\ ${ }^{3}$ Department of Metallurgy and Materials Engineering, Universitas Indonesia, UI Depok New \\ Campus, Depok 16424, West Java, Indonesia \\ * Department of Metallurgy and Materials Engineering, Universitas Indonesia, UI Depok New \\ Campus, Depok 16424, West Java, Indonesia
}

\begin{abstract}
Polyurethanes are one of many types of polymers that are currently being developed worldwide. Some studies reported many substances involved in synthesizing polyurethanes (PU), with mostly originated from a biomass substance. Our laboratory has synthesized natural fiber - based PU to obtain hybrid PUs through varying reaction variables such as temperature. This study used cellulose, a biomass substance as well as polyethylene glycol and 4,4' methylenebis cyclohexyl isocyanate (HMDI) in synthesizing the hybrid PU, and investigated their thermal stability such as decomposition temperature by Differential Scanning Calorimetry (DSC) showed various tendency according to the chain extending temperature for the decomposition temperature. Simultaneous Thermal Analysis (STA) showed glass transition tendency of the product is proportional to the chain extending temperature, where the maximum glass transition obtained from the experimental is $59.8^{\circ} \mathrm{C}$ at $70^{\circ} \mathrm{C}$ of polymerization. Evaluation of functional group in the hybrid PUs was conducted with FT - IR spectroscopy measurement indicating urethane presence as part of the hybrid PUs.
\end{abstract}

\section{Introduction}

Biomass - based PUs are currently being developed through various studies [1 - 3]. The vast possibilities of many biomass substance to be processed into a polyol for polyurethanization means, and many ways to synthesize PU with a sustainable development. Previous studies about polyurethanes included the use of the product of the self - metathesis of soybean oil (MSBO) based polyol to make polyurethane foams [4], organocatalysis in synthesizing 
thermoresponsive polyurethanes [5], soy - oil and caster - oil based polyol for novel shape - memory thermoplastic PUs [6], Canola - oil based diol (COBD) for thermoplastic PUs [7], and castor oil based polyol for rigid polyurethanes [8].

Currently, chain extenders in polyurethanization has also being widely developed, using some compounds such as precipitated silica with silanol groups [9], $n$ - butanediol (BDO) [10], IDD - diols [11], dithioerythritol [12], and diamine [13] to the biomass - based substance such as cellulose originated from sorghum bicolor plant [14]. Cellulose grafting has also been studied to investigate the effects of graft chain length on thermal behaviour [15]. The availability of cellulose as a grafting substance as well as chain extender in polyurethanization proves the ability of cellulose as a substance available for creating an environmentally friendly PU material [14]. There is also a conducted study focusing on preparation for microfibrilated celluloses based on Arenga Pinnata "ijuk" fiber [16], as well as a study about modified shape memory polyurethane using $\mathrm{Fe}_{3} \mathrm{O}_{4}$ nanoparticles [17].

Previous study conducting cellulose as a chain extender in synthesizing polyurethane has not yet conduct the temperature optimization in the polyurethanization. The thermal properties of the cellulose - fiber based hybrid PU and expected change in glass transition due to variations in the polyurethanization is the aim of study of the polyurethanization temperature optimization, specifically when reacting the prepolymer and chain extender to synthesize the hybrid PU. The temperature variations in the polyurethanization are $50^{\circ} \mathrm{C}$, $70^{\circ} \mathrm{C}, 80^{\circ} \mathrm{C}$, and $90^{\circ} \mathrm{C}$. The synthesized hybrid PUs with temperature optimization were then investigated with Simultaneous Thermal Analysis (STA) for thermal characterization, and Fourier Transform - Infra Red (FT - IR) to investigate the existence of urethane group in the hybrid PUs.

\section{Experimental}

\subsection{Materials}

The main raw materials for polyurethanization are polyethylene glycol with molecular weight of 6000 mole (PEG 6000), 4, 4' - Methylenebis cyclohexyl isocyanate (HMDI) with purity of $90 \%$, dimethyl formamide (DMF) 99.8\%, dibutyltin dilaurate (DD) 95\%, and cellulose powder. All raw materials but DMF and cellulose powder were obtained from Sigma Aldrich, with DMF and cellulose powder obtained from Merck. No pre - process conducted before the synthesis of the hybrid PU.

\subsection{Synthesis of Hybrid Polyurethane}

The total time needed for all process is $5 \mathrm{~h}$, and is based on previous study conducted by $\mathrm{F}$. H. Ikhwan, et. al ${ }^{[11]}$. The first process was to dissolve PEG 6000 with DMF in temperature of $70^{\circ} \mathrm{C}$ for $2 \mathrm{~h}$. The second process was to synthesize the pre $-\mathrm{PU}$ by reacting the dissolved PEG 6000 with HMDI in temperature of $70^{\circ} \mathrm{C}$ for $2 \mathrm{~h}$. The last process was to synthesize the hybrid PU by reacting the pre - PU obtained from the previous process with cellulose powder in several temperatures; $50^{\circ} \mathrm{C}, 70^{\circ} \mathrm{C}, 80^{\circ} \mathrm{C}, 90^{\circ} \mathrm{C}$. All of the process were conducted in Schlenk tubes, dipped and heated in oil bath. Right after each process were conducted, fluxing was conducted together with nitrogen atmosphere to make vacuum condition inside the Schlenk tubes.

After all of the process were conducted, the sample in the form of white milk solution was obtained. Phase separation was then conducted by terminating the product with $20 \mathrm{ml}$ of water and left intact until $24 \mathrm{~h}$ when the hybrid PU precipitated and separated before dried for 3 days and continued with characterization. 


\subsection{Characterization}

Fourier Transform - Infra Red (FTIR) was used to investigate the existence of urethane group within the hybrid PU. The investigation was conducted in DTMM FTUI using FTIR PerkinElmer UATR Two Spectrum Two which has a limitation of wavelength ranging from $400-4000 \lambda$. Simultaneous Thermal Analysis was used to investigate the glass transition (Tg) and thermal stability of the hybrid PU. The investigation was conducted in DTMM FTUI using STA PerkinElmer STA6000 which has a rate limitation of $5 \mathrm{~min} /{ }^{\circ} \mathrm{C}$ and $\max$ temperature of $1000^{\circ} \mathrm{C}$.

\section{Result and Discussion}

Polyurethanization was carried out by two steps of process. The first being pre polyurethanization which is the process to synthesize the pre - PU by reacting soft segment and hard segment, and the other being copolyurethanization or chain extending which is the process to synthesize the hybrid PU by reacting pre - PU obtained from the previous step with a chain extender. In this study, PEG 6000 serves as the soft segment, HMDI as the hard segment, and cellulose as the chain extender. The synthesized hybrid PUs were then evaluated by Simultaneous Thermal Analysis (STA) to investigate the glass transition temperature and Fourier Transform - Infra Red (FT - IR) to investigate the existence of urethane group in the hybrid PUs.

\subsection{Structure of Hybrid Polyurethanes}

Figure 1 shows FTIR spectra for each hybrid PUs, indicating the existence of chemical bonds in the hybrid PUs. Ether (C-O) are found at $1241 \mathrm{~cm}^{-1}$ as a typical indicator of successful reaction for pre - PU and cellulose. Amine $\left(\mathrm{NH}_{3}\right)$ bonds at $1279-1343 \mathrm{~cm}^{-1}$, and secondary amine at $2884 \mathrm{~cm}^{-1}$ proved the existence of isocyanate $(\mathrm{N}=\mathrm{C}=\mathrm{O})$ parts, as urethane group in the hybrid PU. Based on the transmission percentage shown by the figures, HPU 70-50 has the least infrared transmission meaning that the bonds present most in HPU 70-50.

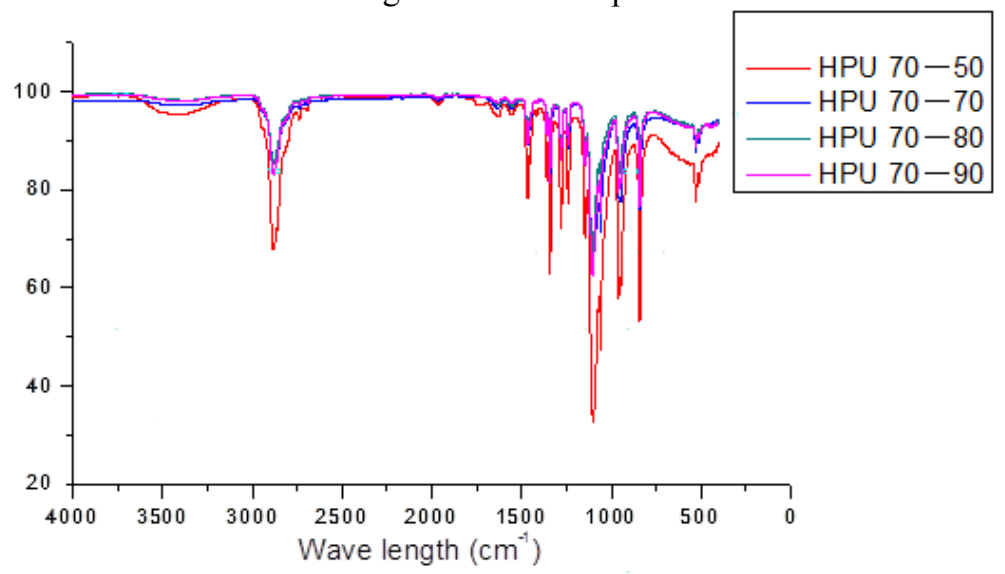

Fig. 1. FTIR Spectra of hybrid polyurethane samples

\subsection{Thermal Behaviour of Hybrid Polyurethane}

Effects of synthesis temperature in cellulose adding to glass transition thermal characteristics of the hybrid PUs were investigated by Differential Scanning Chromatography (DSC), as 
shown in Fig. 2. At the beginning the increase in synthesis temperature enhances the glass transition temperature $(\mathrm{Tg})$ which is shown the glass transition temperature of HPU 70-50 and HPU 70-70. However, this tendency undergoes a change into decreasing with the temperature enhancement (see $80^{\circ} \mathrm{C}, 90^{\circ} \mathrm{C}$ shown in HPU 70-80 and HPU 70-90). The tendency was caused by the thermal degradation that occurred in the cellulose above $70^{\circ} \mathrm{C}$.

Table 1. DSC analysis results on hybrid polyurethane

\begin{tabular}{c|c}
\hline Sample & $\operatorname{Tg}\left({ }^{\circ} \mathrm{C}\right)$ \\
\hline HPU 70-50 & 52.13 \\
HPU 70-70 & 59.8 \\
HPU 70-80 & 59.29 \\
HPU 70-90 & 58.84 \\
\hline
\end{tabular}



Fig. 2. Glass Transition Temperature Graph

\subsection{Thermal Stability Analysis}

Thermogravimetric analysis was utilized to analyse furthermore thermal stability of the hybrid PU products. The result of the test was shown as a graph (fig. 3) that shows the reducing of polyurethane mass against temperature. According to the graph, it can be seen that HPU 70-90 has the best thermal stability, followed by HPU 70-80, HPU 70-70, and HPU 70-50. However, the weight reduction shows otherwise. It is predicted that due to the low temperature in the synthesis of HPU 70-50, the bonds present in the HPU did not weaken prior to thermogravimetric analysis. Thermal stability however, increase proportionally to the increase of chain extending temperature for the first decomposition phase, but decrease for chain extending at $80^{\circ} \mathrm{C}$ and $90^{\circ} \mathrm{C}$ for the second decomposition phase, and at the third decomposition phase $80^{\circ} \mathrm{C}$ has the lowest decomposition temperature shown by fig. 4 .

Table 2. Decomposition temperature (Td) on hybrid polyurethane

\begin{tabular}{c|c|c|c}
\hline $\begin{array}{c}\text { Chain Extending } \\
\text { Temperature }\left({ }^{\circ} \mathrm{C}\right)\end{array}$ & $\begin{array}{c}\mathrm{Td}_{1}\left({ }^{\circ} \mathrm{C}\right) / \text { Weight } \\
\text { Reduction }(\%)\end{array}$ & $\begin{array}{c}\mathrm{Td}_{2}\left({ }^{\circ} \mathrm{C}\right) / \text { Weight } \\
\text { Reduction }(\%)\end{array}$ & $\begin{array}{c}\mathrm{Td}_{3}\left({ }^{\circ} \mathrm{C}\right) / \text { Weight } \\
\text { Reduction }(\%)\end{array}$ \\
\hline HPU 70-50 & $302.19 / 8$ & $378.77 / 25$ & $429.69 / 89$ \\
HPU70-70 & $304.27 / 3.2$ & $381.48 / 18.75$ & $432.8 / 92.5$ \\
HPU 70-80 & $320.07 / 16.6$ & $373.73 / 37.37$ & $424.06 / 82$ \\
HPU 70-90 & $325.15 / 5.7$ & $370.35 / 16.67$ & $426.33 / 90$ \\
\hline
\end{tabular}




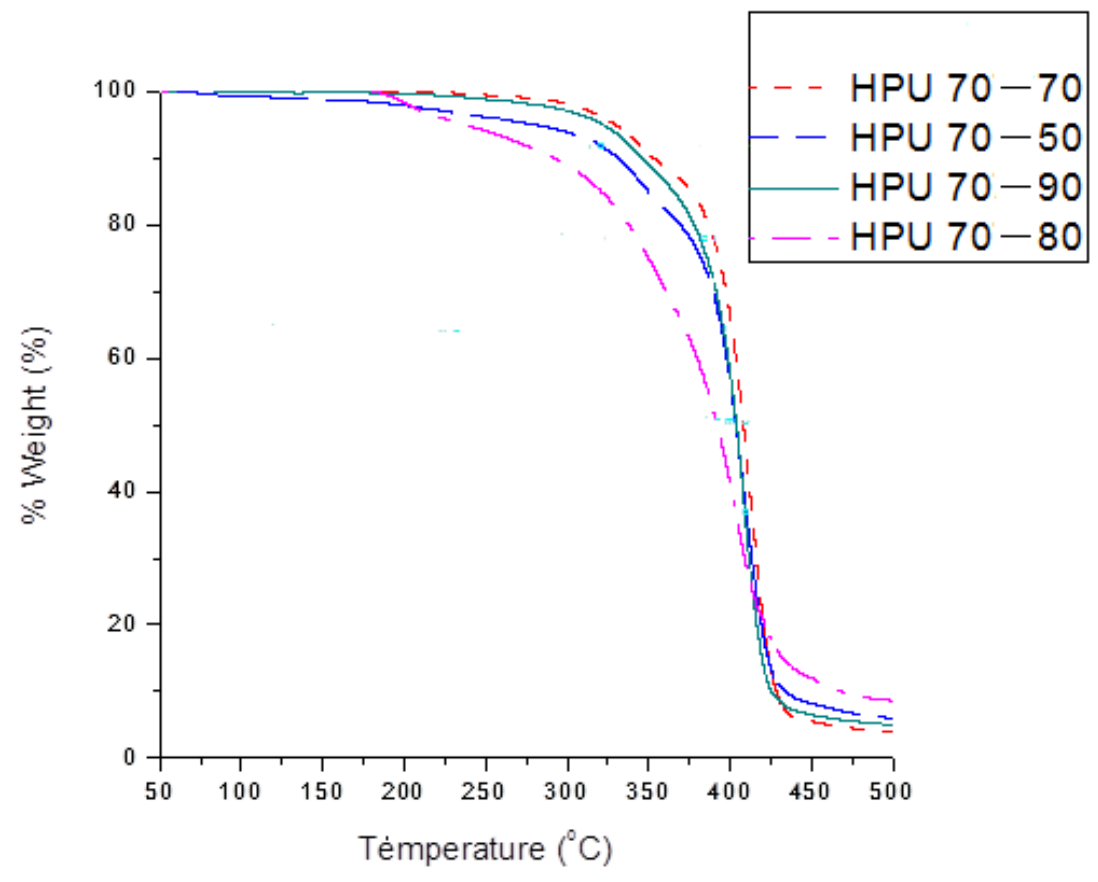

Fig. 3. Variations of Chain Extending Temperature TGA Curve

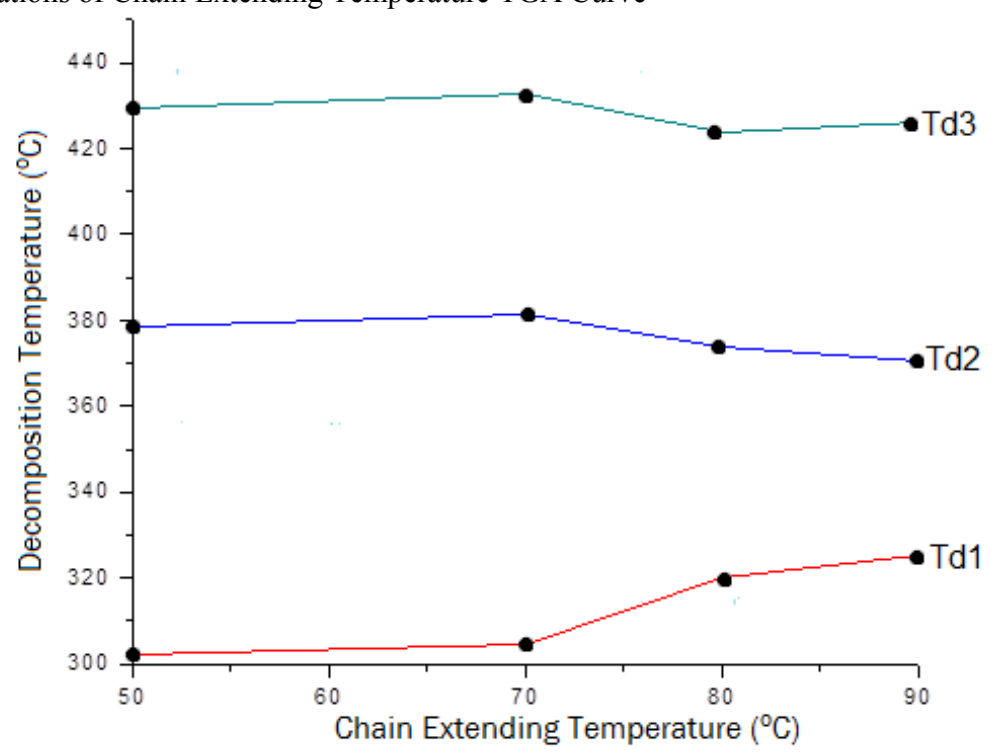

Fig. 4. Decomposition Temperature Graph

The first decomposition phase shows that higher chain extending temperature results in more reaction to take place and increase bonds, this is shown in fig. 4 for $90^{\circ} \mathrm{C}$ had the highest decomposition temperature in the first decomposition phase. The cause for the phenomenon in second decomposition phase is caused by the less significant effect of pyrolytic resistance. 
PEG 6000 has a good thermal stability because it has a relatively high molecular weight, but it also comes with a consequence; pyrolytic resistance becomes less significant. Pyrolytic resistance is a property that gives improvement to thermal stability [17]. The decrease in pyrolytic resistance is the cause of the decrease in decomposition temperature for chain extending at $80^{\circ} \mathrm{C}$, and $90^{\circ} \mathrm{C}$. The phenomenon in the third decomposition phase was caused by thermal degradation in the cellulose. While higher chain extending temperature triggered more reaction to take place, thermal degradation may occur in cellulose above $70^{\circ} \mathrm{C}$.

\section{Conclusion}

Cellulose - fiber hybrid polyurethanes have been synthesized in different temperatures and evaluated by DSC and TGA. FTIR testing was also conducted to find out the bonds inside the hybrid polyurethanes. All bonds required to acknowledge the urethane group are present in all of the samples. Variation in chain extending temperature give influence in the glass transition temperature and thermal stability.

\section{References}

[1] M. Chalid, H. J. Heeres, A. A., Broekhuis, Polymer - Plastic Technology and Engineering 54 (2015)

[2] M. Chalid, H. J. Heeres, A. A., Broekhuis, Applied Mechanics and Materials 229 - 231 $297-302(2012)$

[3] S. Ilmiati, J. H. Mustafa, A. Yaumal, F. Hanum, M. Chalid, IOP Conference Series: Materials Science and Engineering 223 (2017) 012033

[4] S. Li, L. Bouzidi, S. S. Narine, Europian Polymer Journal 93232 - 245 (2017)

[5] L. I. Ronco, A. Basterretxea, D. Mantione, R. H. Aguirresarobe, R. J. Minari, L. M. Gugliotta, D. Mecerreyes, H. Sardon, Polymer 122117 - 124 (2017)

[6] Z. S. Petrović, J. Milic, F. Zhang, J. Ilavsky, Polymer 12126 - 37 (2017)

[7] M. B. Karimi, G. Khanbabaei, G. M. M. Sadeghi, Journal of Membrane Science 527198 $-206(2017)$

[8] M. Ionescu, D. Radojčić, X. Wan, M. L. Shrestha, Z. S. Petrović, T. A. Upshaw, Europian Polymer Journal 84736 - 749 (2016)

[9] L. Chen, X. Wang, Z. Jia, Y. Luo, D. Jia, Materials \& Design 87324 - 330 (2015)

[10] N. Lempesis, P. J. in 't Veld, G. C. Rutledge, Polymer 107233 - 239 (2016)

[11] Chien - Hsin Wu, Yu - Ching Chen, S. A. Dai, Su - Chen Chen, Shih - Huah Tung, Rong - Ho Lee, Wen - Chiung Su, Ru - Jong Jeng, Polymer 1191 - 12 (2017)

[12] L. H. Chan - Chan, R - Sollis Correa, R. F. Vargas - Corronado, J. M. Cervantes - Uc,

J. V, Cauich - Rodriguez, P. Quintana, P. Bartolo - Perez, Acta Biomateriala 62035 - 2044

[13] L. Lei, Y. Zhang, C. Ou, Z. Xia, L. Zhong, Progress in Organic Coatings 9285 - 94 (2016)

[14] F. H. Ikhwan, S. Ilmiati, H. K. Adi, R. Arumsari, M. Chalid, IOP Conference Series: Materials Science and Engineering 223 (2017) 012019

[15] M. H. Ryu, J. Park, D. X. Oh, S. Y. Hwang, H. Jeon, S. S. Im, J. Jegal, Polymer Degradation and Stability 142226 - 233 (2017)

[16] E. Yuanita, J. N. Pratama, J. H. Mustafa, M. Chalid, Procedia Chemisty $16608-615$ (2015)

[17] D. F. Firdaus, Masrudin, D. A. Lestari, M. R. Arbi, M. Chalid, Indo. J. Chem. 15130 140 (2017)

[18] C. Yuan, M. Z. Rong, M. Q. Zhang, Polymer 551782 - 1791 (2014) 